\title{
Intraoperative Frozen Section for the Evaluation of Extrathyroidal Extension in Papillary Thyroid Cancer
}

\author{
Om Prakash Prajapati • A. K. Verma • \\ M. Sabaretnam
}

Published online: 8 January 2015

(c) Société Internationale de Chirurgie 2015

We read with interest the article by Park Y M et al., "Intraoperative frozen section for the evaluation of extrathyroidal extension in papillary thyroid cancer" [1]. We congratulate the authors on their novel technique of using an already existing technique and bringing it from the bench to bedside for the betterment of treatment of papillary thyroid cancer. Extrathyroidal extension especially minimal ETE has been a matter of great debate among endocrine surgeons and endocrine pathologists, considering the definition and also the prognosis especially in small tumors [2].

We have few queries which shall be of benefit for future readers. Since many different criteria are available for ETE and controversy exists in the definition of minimal ETE (involvement of adipose tissue and skeletal muscle is still a controversy, and involvement of sizable vascular structure and small peripheral nerves are considered as minimal ETE $[3,4]$ ), we would like to know which criteria were used by the authors and also the definition of minimal ETE.

Did the authors find any correlation between the variants of papillary thyroid carcinoma and extrathyroidal extension since aggressive variants have more ETE? False negative rate of frozen biopsy was $12.62 \%$. Did a dedicated Pathologist report or review these reports?

\section{References}

1. Park YM, Wang SG, Goh JY, Shin DH, Kim IJ, Lee BJ (2015) Intraoperative frozen section for the evaluation of extrathyroidal extension in papillary thyroid cancer. World J Surg 39:187-193. doi:10.1007/s00268-014-2795-5

2. Nixon IJ, Ganly I, Patel S, Palmer FL, Whitcher MM, Tuttle RM, Shaha AR, Shah JP (2011) The impact of microscopic extrathyroid extension on outcome in patients with clinical T1 and T2 welldifferentiated thyroid cancer. Surgery 150(6):1242-1249. doi:10. 1016/j.surg.2011.09.007

3. Ghossein R (2009) Update to the College of American Pathologists reporting on thyroid carcinomas. Head Neck Pathol 3(1):86-93

4. Jeon HM, Lim BJ, Chang HS, Hong S (2012) The definition of minimal extrathyroid extension in thyroid pathology by analyzing sizable intra- and extrathyroid blood vessels. Korean J Pathol 46(6):548-553
O. P. Prajapati · A. K. Verma · M. Sabaretnam ( $ه)$

Endocrine Surgery Department, Sanjay Gandhi Postgraduate

Institute of Medical Sciences, Lucknow, India

e-mail: drretnam@gmail.com 